\title{
PROPUESTA DE RESTITUCIÓN DEL ANFITEATRO DE ITÁLICA SEGÚN LAS NUEVAS APORTACIONES ${ }^{1}$
}

\section{PROPOSAL FOR RESTITUTION OF THE ITALICA AMPHITHEATRE ACCORDING TO THE NEW CONTRIBUTIONS}

\author{
Dr. José David Mendoza Álvarez ${ }^{2}$ \\ Universidad de Sevilla \\ DOI: 10.17533/udea.tempus.n7a06
}

\section{Resumen}

El anfiteatro de Itálica, Santiponce (Sevilla, España), ha sido la figura más emblemática de las ruinas de la ciudad romana fundada por Escipión en el contexto de la II Guerra Púnica, en el año 206 a.C., pasando a ser también la figura más representativa del Conjunto Arqueológico de Itálica en la actualidad, aunque no por ello ha sido el edificio más estudiado. De esta manera, se ha realizado una nueva investigación reciente con resultados novedosos sobre su nueva restitución que presentamos en estas líneas, aportando principalmente la arquitectura de los restos hoy día desaparecidos, gracias a una labor de investigación histórica, historiográfica y arqueológica, en el que determinaremos la existencia de una estructura intermedia entre las cáveas que hemos denominado cuerpo intermedio.

Palabras clave: Imperio Romano, Arqueología, Historia, Historiografía, Anfiteatro.

\begin{abstract}
The Itálica amphitheater, Santiponce (Seville, Spain), has been the most emblematic figure of the ruins of the Roman city founded by Escipión in the context of the Second Punic War, in $206 \mathrm{BC}$, becoming also the most representative figure of the Itálica Archaeological Complex at present, although it has not been the most studied building. In this way, a new recent investigation has been carried out with novel results on its new restitution that we present in these lines, contributing mainly to the architecture of the remains that have disappeared today, thanks to historical, historiographical and archaeological research work, in which we will determine the existence of an intermediate structure between the caveas that we have denominated intermediate body.
\end{abstract}

Keywords: Roman Empire, Archeology, History, Historiography, Amphitheatre.

\footnotetext{
${ }^{1}$ Artículo recibido el 15 de febrero de 2018; aprobado el 25 de abril de 2018

${ }^{2}$ Doctor en Arqueología por la Universidad de Sevilla e investigador en grupo RNM-162 de la Escuela Técnica Superior de Arquitectura de la Universidad de Sevilla. Correo: luckyman76@hotmail.com
} 


\section{Introducción}

Presentamos una propuesta de restitución para el anfiteatro de Itálica, Santiponce (Sevilla, España), gracias a las nuevas aportaciones que se han desarrollado en el edificio recientemente, que lo configuran en una peculiar edilicia con cronología adrianea. Se ubica al norte de la ciudad de Itálica, en el exterior de la ampliación llevada a cabo en tiempos del emperador Adriano (117-138), y denominada en la actualidad como Nova Urbs para diferenciarla de la ciudad anterior a este emperador o Vetus Urbs. Esta ciudad se muestra de suma importancia para la Historia, pues se trata de la primera colonia romana fundada fuera de la Península Itálica, en el año 206 a.C., tras la batalla de Ilipa ${ }^{3}$, Alcalá del Río (Sevilla, España), que enfrentó a romanos y cartagineses en el contexto de la II Guerra Púnica y que significó la victoria de los primeros y el fin de la contienda en los límites de la Península Ibérica. En esta nueva fundación, Escipión el Africano acantonó a sus heridos de combate y la denominó Itálica en honor a la procedencia de sus soldados. ${ }^{4}$

La ciudad se creó sobre un oppidum turdetano ${ }^{5}$ existente desde el siglo V-IV a.C., siendo elevada a la condición de municipio bajo Augusto $^{6}$ por haber servido al bando cesariano en las guerras civiles como se cree generalmente, y con Adriano se elevó a colonia $^{7}$, recogido por Aulo Gelio ${ }^{8}$ y reflejado en la epigrafía (CIL II, 1135; CIL XI, 2699; CIL XII, 1856) entre otros ejemplos. ${ }^{9}$ Se ubica en altura, en un lugar estratégico desde donde se domina la Vega del Guadalquivir. ${ }^{10}$ Con el tiempo, la ciudad amplió sus límites y fue embellecida por distintos emperadores, como Augusto que monumentalizó gran parte de la misma, destacando el teatro, o Trajano que hizo lo propio, pero no sería hasta

\footnotetext{
${ }^{3}$ Apiano, Iber., 38

${ }^{4}$ José María Blázquez, Religiones en la España antigua (Madrid: Cátedra, 1991), 285-286; José Manuel Rodríguez Hidalgo y Simon Keay, "Recent work at Italica", Proceedings of the British Academy, n. 86 (1995): 397.

${ }^{5}$ En contra de lo que se estimaba, Itálica no se erigió junto a un núcleo turdetano, sino sobre el propio asentamiento turdetano. Véase al respecto Juan Manuel Abascal Palazón y Urbano Espinosa Ruiz, La ciudad hispano-romana (Logroño: Privilegio y Poder, 1989), 27.

${ }^{6}$ Con Augusto sería elevada al rango de municipio junto a un programa urbanístico monumental, aunque se debe tener en cuenta si se trataba de un Municipium Iuris Latini o un Municipium Ciuium Romanorum. Véase sobre la cuestión la obra de Rodríguez y Keay, "Recent work at Italica", 399.

${ }^{7}$ Manuel Morales Cara, La esclavitud en las colonias romanas de Andalucía (Granada: Universidad de Granada, 2005), 455; Luis Amela Valverde, "Pompeius Niger de Italica", Cuadernos de filología clásica: Estudios latinos v. 31, n.1 (2011): 31.

${ }^{8}$ Noctes Atticae, XVI, 13.4

9 Antonio Blanco Freijeiro, "La Itálica de Trajano y Adriano (Santiponce, Sevilla)", en: Actas de las primeras jornadas sobre excavaciones arqueológicas en Italica, Exma. Diputación Provincial de Sevilla, 1980 (Madrid: Ministerio de Cultura, 1982), 308.

10 Antonio García y Bellido, Andalucía Monumental: Itálica (Granada: Editoriales Andaluzas Unidas, 1960), 21.
} 
la llegada de Adriano como emperador, quien nunca visitó su patria chica tras tomar posesión de la púrpura imperial a pesar de que sus familiares directos procedían de la propia Itálica, cuando se ampliaron sus límites, otorgándola con grandes dones y excepcionales monumentos nuevos como el Traianeum, el circo, las denominadas termas mayores, y por supuesto, el anfiteatro. Nosotros no entraremos a cuestionar la polémica sobre a la figura de Adriano en cuanto a su procedencia, pues para unos autores nació en Itálica y para otros en Roma. La ampliación adrianea o Nova Urbs, de trazado helenístico con amplias calles y casas porticadas, se extendía al norte de la ciudad trajanea, adaptándose a la topografía del terreno. Y al exterior de la misma, en el norte, se construyó el anfiteatro el cual presentaba parte de su graderío apoyando en dos cerros norte-sur, y una orientación este-oeste. La arquitectura respondía a una edilicia adrianea en la que señalaremos los paralelos más inmediatos conforme vayamos planteando nuestras hipótesis.

El anfiteatro se torna como el objeto de nuestra investigación, por lo que destacaremos las pautas que nos ha llevado a conformar nuestra propuesta de restitución. Los restos que actualmente observamos no son muy numerosos. Aparentemente se aprecia una gran mole de opus caementicium, el hormigón romano, conformando una entrada principal al este, que ha sido restaurada desde los años treinta del siglo XX, aunque sin llegar a mantener ninguna arcada en pie. No obstante conserva su planta en gran parte, pues aún muestra muchas zonas por excavar y otras mantenidas a duras penas con pilastras para contener los desplomes. En el interior se aprecia un primer cuerpo con ocho filas de gradas aunque despojado de sus mármoles originarios, y gran parte del segundo cuerpo el cual tenía catorce filas de gradas, conservadas en un solo punto al sureste, aunque se preservan los vomitoria o accesos al graderío y se distinguen los cunei que componía cada cávea. Al oeste, el sector principal se muestra mejor conservado, aunque está condicionado por el dique artificial que se erigió a mediados del siglo XIX para evitar las inundaciones, y acondicionado desde los años setenta hasta finales de la primera década del siglo XXI.

A lo largo de su historia, el anfiteatro ha sufrido numerosos avatares, desde la utilización como cantera de sus restos a las excavaciones incontroladas y expolio. Sería el siglo XIX el momento de mayor destrucción del mismo y a la vez el siglo en el que comenzarían las principales excavaciones y medidas de protección. Pero un hecho de suma importancia ha pasado desapercibido en las investigaciones y nos ha permitido 
establecer nuestras hipótesis y proporcionar una nueva restitución de este insigne edificio. Se trata de la gran colmatación que lo protegía paulatinamente de cada acometida para extraer sus restos, constatándose un primer nivel a una altura de 18 metros sobre el nivel de la arena (debemos aclarar que en ningún momento hablaremos de metros sobre el nivel del mar), para el siglo XVI, y de unos 8 metros a mediados del siglo XIX.

\section{Momentos iniciales de los anfiteatros}

En el mundo griego se configuraron los espectáculos deportivos, adaptados por los intercambios culturales entre los etruscos quienes a su vez lo transmitieron a los romanos en el siglo III d.C., para los contextos funerarios en un primer momento, donde se realizaban luchas, duelos o carreras de caballos, aunque posteriormente se fue configurando como espectáculos meramente lúdicos siendo considerados como una herramienta política de control de masas y sus actividades ampliadas y distribuidas en una serie de edificios que se fueron acondicionando a ellos, como los circos, teatros, naumachiae o anfiteatros. ${ }^{11}$ La violencia de los espectáculos y la exhibición de animales requirieron espacios adaptados a ellos, pues comenzaron a ofrecerse en los foros ${ }^{12}$ acondicionando espacios rectangulares ${ }^{13}$, lo que dificultaba la visión. Esto motivó la creación de edificios en primer lugar con formas circulares y posteriormente confeccionando formas geométricas ovaladas o elípticas donde el ángulo de visión sería corregido así como la seguridad de los espectáculos. ${ }^{14}$

Sería en el Campo de Marte donde se construyó un gran anfiteatro de la mano de Cayo Statilio Tauro, en época augustea, que fue destruido en el incendio en tiempos de

\footnotetext{
${ }^{11}$ Antonio María Fabié, "El nuevo bronce de Itálica", Boletín de la Real Academia de la Historia, n. 21 (1892): 392; José María Blázquez, "Posibles precedentes prerromanos de los combates de gladiadores romanos", en Bimilenario del anfiteatro Romano de Mérida. Coloquio Internacional el anfiteatro en la Hispania Romana. Mérida, 26-28 de noviembre de 1992, coord. José María Álvarez Martínez y Juan Javier Enríquez Navascués (Mérida: Junta de Extremadura, 1994), 31; José María Blázquez, "Introducción a los escenarios en la antigua Grecia”, en Escenarios de España. Fomento de construcciones y contratos, ed. José María Blázquez (Madrid: Biblioteca Virtual Miguel de Cervantes, 2006), 26; Alberto Ceballos Hornero y David Ceballos Hornero, "Los espectáculos del anfiteatro en Hispania", Iberia v. 6 (2003): 57; Joaquín Gómez-Pantoja, "Entre Italia e Hispania: los gladiadores", en Hiberia-Italia, Italia-Hiberia, ed. Antonio Sartori y Alfredo Valvo (Milán: Cisalpino Istituto Editoriale Universitario, 2006), 169; Alberto Ceballos Hornero, "El coste de los espectáculos gladiatorios en las ciudades del occidente romano", Archivo Español de Arqueología v. 80 (2007): 107; Francisco Pina Polo, "Los espectáculos agonísticos en el occidente del Imperio romano", Salduie, n. 7 (2007): 143-156; Narciso Santos Yanguas, "La nueva gladiatura cristiana en el marco de la gladiatura romana", Hispania Antiqua, n. 32 (2008): 188; Javier Cabrero Piquero y Félix Cordente Vaquero, "Los oficios de la diversión en Roma", Espacio, tiempo y forma. Serie II: Historia Antigua, n. 24 (2011): 363.

12 Tito Livio, XXVIII, 21.

13 Joaquín García Naranjo, El anfiteatro romano de Itálica. Conferencia de divulgación arqueológica (Sevilla: Editorial SE, 1951), 8.

${ }^{14}$ Mark Wilson Jones, “Designin Amphitheatres”, Römische Mitteilungen v. 100 (1993): 391-392.
} 
Nerón. Previamente en el 53 a.C. se había construido un sistema que permitía girar dos teatros de maderas levantados sobre mecanismos adecuados, para enfrentar sus scaenae donde se realizaban los espectáculos, de la mano de Cayo Curio Escriboniano, originándose de esta forma el significado de la palabra anfiteatro. ${ }^{15}$ Posteriormente destacaron estos edificios mediante su edilicia en piedra que soportaba muy bien el peso de los espectadores para evitar tragedias como el desplome de las gradas de madera por no poder con el peso de un gran número de espectadores en algunos casos o los incendios en otros. Gracias a un entramado de arcos y bóvedas en piedra y cemento, fue posible la construcción en altura de estos edificios. ${ }^{16}$

En la Península Ibérica estos edificios se vertebran a lo largo de las vías de comunicaciones más importantes donde se ubicaban las grandes ciudades. ${ }^{17}$ En estos nuevos edificios podían darse juegos gladiatorios o munus, venationi, exhibiciones de animales, ejecuciones, representaciones escénicas, danzas, carreras de caballos y para determinados anfiteatros se realizaron combates navales o naumachias $^{18}$, aunque esto último no era habitual pues para ello se realizaron edificios acondicionados a tal efecto $^{19}$, debiéndose indicar que en Itálica nunca se dieron estos espectáculos navales. ${ }^{20}$ Los anfiteatros eran espacios considerados como fuente de disturbios, teniendo en Pompeya el ejemplo más radical cuando, debido a unos violentos disturbios en su interior con los vecinos de Nocera que acudieron al evento en el año 59, el Senado determinó su cierre como sanción durante diez años. ${ }^{21}$

Estos edificios estaban conformados tradicionalmente con una arena donde se realizaban los espectáculos, un podium elevado para evitar el contacto con los espectadores, continuado por las cáveas divididas en tres sectores según las clases, e internamente conformado con un entramado de galerías abovedadas con una finalidad arquitectónica para soportar el peso, la tensión y los empujes del resto de la estructura. ${ }^{22}$

\footnotetext{
${ }^{15}$ Cabrero y Cordente, "Los oficios de la diversión...", 369.

${ }^{16}$ Santos, "La nueva gladiatura...", 188.

17 Alberto Ceballos Hornero, "Geografía y cronología de los ludi en la Hispania romana”, Caesaraugusta, 78 (2007a): 442.

${ }^{18}$ Ceballos y Ceballos, "Los espectáculos del anfiteatro...”, 57; Javier Garrido Oreno, "El anfiteatro: una oscura imagen de la antigua Roma", Berceo v. 149 (2005): 162; Blázquez, "Introducción a los escenarios...", 26; Cabrero y Cordente, "Los oficios de la diversión...", 364.

${ }^{19}$ Suetonio, Caes. 39 y 44; Marcial, Epigr. 26 y 28.

${ }^{20}$ Cabrero y Cordente, "Los oficios de la diversión...", 372.

${ }^{21}$ Cabrero y Cordente, "Los oficios de la diversión...", 369.

${ }^{22}$ García, El anfiteatro..., 10; Pierre Gross, "L’amphitheâtre dans la ville. Politique "culturelle" et urbanisme aux deux premiers siècles de l'Empire", en Bimilenario del anfiteatro Romano de Mérida. Coloquio Internacional el anfiteatro en la Hispania Romana. Mérida, 26-28 de noviembre de 1992, coord.
} 
La élite ocuparía la ima cavea con mejores vistas, la segunda cávea solía estar compuesta de catorce filas de gradas reservadas para los caballeros como indicaba la lex Roscia, y la summae cavea se destinaba a los ciudadanos libres y masculinos, quedando el porticus in summae cavea reservado a mujeres, niños y esclavos. Por lo general, los anfiteatros solían disponer de un velamen para proteger del sol a los espectadores, extendido desde la terraza superior.

\section{Nuevas aportaciones para la restitución del anfiteatro italicense}

Como ya hemos comentado, el anfiteatro de Itálica se sitúa al norte de la actual ciudad de Santiponce, en la ampliación adrianea, con una dirección este-oeste. ${ }^{23}$ Debemos destacar las condiciones topográficas del sitio donde se ubica el anfiteatro ${ }^{24}$, hecho fundamental a la hora de entender cómo se ha conservado el edificio en sus niveles inferiores a pesar del gran expolio sufrido durante siglos, pues el edificio se construye aprovechando dos cerros donde previamente se canalizó el arroyo que entre los mismos discurría $^{25}$, siendo necesaria el acondicionamiento de estos cerros en una forma llamada por Golvín y utilizada por otros investigadores como estructura mixta. ${ }^{26}$

El análisis de textos, fuentes históricas, ilustraciones, grabados y archivos, ha sido crucial a la hora de establecer una restitución científica del anfiteatro de Itálica. Por ello, nuestro trabajo inicial consistió en la recopilación de materiales desde el siglo XVII hasta nuestros días, centrándonos en los archivos oficiales del siglo XIX como punto de

José María Álvarez Martínez y Juan Javier Enríquez Navascués (Mérida: Junta de Extremadura, 1994), 13; Francisco Beltrán Lloris, Lo mejor del Arte Romano I (Madrid: Historia 16, 1997), 28.

${ }^{23}$ Rodrigo Amador de los Ríos, "El anfiteatro de Itálica", Revista de Archivos, Bibliotecas y Museos, $3^{a}$ época v. 20, n. 34 (1916): 381; Nieves Chisvert Jiménez, Topónimos de Italica: urbanismo y arquitectura (Sevilla, 1987), 282; Jaime Muñoz Garrido, El proyecto romano construido en Lusitania (Madrid: Universidad Politécnica de Madrid, 2002), 246.

${ }^{24}$ De Los Ríos, "El anfiteatro de Itálica...", 406.

25 Jean-Claude Golvin, L 'Amphitheatre Romain (París: Centre Pierre Paris, 1988), 200; Lourdes Roldan Gómez, "El anfiteatro de Itálica. Técnicas y materiales de construcción", en Bimilenario del anfiteatro Romano de Mérida. Coloquio Internacional el anfiteatro en la Hispania Romana. Mérida, 26-28 de noviembre de 1992, coord. José María Álvarez Martínez y Juan Javier Enríquez Navascués (Mérida: Junta de Extremadura, 1994), 215; Enrique Larrey Hoyuelos, Francisco Ramón Girón y Javier Verdugo Santos, "Intervención arqueológica en el anfiteatro de Itálica. Campaña de 1998", Anuario Arqueológico de Andalucía de 1998 v. 3 (1998): 1081; Manuel Pellicer Catalán, "Panorama de la arqueología de Itálica", Boletín de la Real Academia de Bellas Artes de Santa Isabel de Hungría v. 27 (1999): 178; Rafael Hidalgo Prieto, "Anfiteatros", en Arte romano de la Bética. Arquitectura y Urbanismo, coord. Pilar León (Sevilla: Fundación Focus Abengoa, 2008), 223.

${ }^{26}$ Golvín, L`Amphitheatre Romain..., 157; Lourdes Roldán Gómez, Técnicas constructivas romanas en Itálica. Santiponce, Sevilla (Madrid: Universidad Autónoma de Madrid, 1993), 98; Jorge Ramón Corzo Sánchez, "El anfiteatro de Itálica", en Bimilenario del anfiteatro Romano de Mérida. Coloquio Internacional el anfiteatro en la Hispania Romana. Mérida, 26-28 de noviembre de 1992, coord. José María Álvarez Martínez y Juan Javier Enríquez Navascués (Mérida: Junta de Extremadura, 1994), 187-192; Tania Bellido Márquez, "Panorama historiográfico del anfiteatro de Itálica", Rómula, n. 8 (2009): 35. 
inflexión en la consideración de la imagen que ha llegado a nuestros días por errores de interpretaciones, y que pretendemos restituir mediante nuestras nuevas propuestas. A continuación y de forma muy breve, comentaremos los dibujos más importantes y las fuentes documentales que nos han permitido establecer tales cuestiones, aunque no sin antes determinar las partes básicas que componen el anfiteatro de Itálica y la nueva arquitectura que pretendemos con este estudio. De forma interna, estos sectores ya conocidos son la arena con su foso bestiario, el podium, la ima cavea con ocho filas de gradas, una primera praecintio y balteus o pequeño muro de separación entre la siguiente grada, la media cavea con catorce filas de gradas, una segunda praecintio, el cuerpo intermedio como nueva aportación, la summae cavea con veinte filas de gradas, el porticus in summae cavea con espacio para seis filas de gradas más, probablemente desmontables, y la terraza desde donde se extendería el velamen. En nuestro estudio determinamos una fachada de perímetro continuo, con planta elíptica a diferencia de los autores que pretenden ver una conformación como óvalo, pues la figura geométrica elíptica admite modificaciones respecto a la adaptación necesaria al terreno ya que hemos de recordar que el anfiteatro italicense apoya parte de su graderío en dos cerros al norte y sur, mientras que sus sectores este y oeste se erigen desde el mismo nivel de la arena. Además, la controvertida escalera perimetral en la que muchos autores la disponen al exterior del edificio como un elemento añadido, nosotros hemos mantenido las premisas de Demetrio de los Ríos que establece que la escalera perimetral transcurría por el interior del edificio, ya que el mismo autor llegó a excavar parte de la fachada externa, como comprobaremos posteriormente.

De esta forma, se presenta un edificio atípico, propio de la edilicia adrianea, en el que no debemos concebirlo como una serie de arcadas abiertas al modo de otros anfiteatros como el Coliseo, sino que al disponer de una escalera perimetral de unos tres metros de ancha, se cerraba el conjunto, manteniendo una configuración de arcadas abiertas y cerradas, con la finalidad de soportar el resto de la estructura. A su vez, la escalera permitía distribuir a los espectadores a los niveles superiores, ya que la ima cavea estaba reservada a la élite como sabemos. La configuración exterior que nos ofrece el edificio sería peculiar, pues en los sectores este y oeste presentaría tres cuerpos mientras que al norte y al sur tan solo dos cuerpos debido a que la primera cávea apoyaría en los cerros. Todo ello terminando en un cuerpo de ático. Por tanto, las entradas se realizarían desde el nivel de la arena en los sectores principales este y oeste, y desde el segundo 
cuerpo en las partes norte y sur, mientras que la escalera perimetral conduciría a unas catorce aperturas en todo su perímetro.

De forma interna debemos señalar la existencia de un nuevo elemento, un cuerpo que se detecta en otros anfiteatros con la misma cronología adrianea y hemos podido determinar para el italicense gracias al análisis que realizamos, señalando que presenta las mismas dimensiones que el cuerpo del podium con el que fue confundido inicialmente. Este elemento, más allá de ser una composición arquitectónica decorativa, se presenta con una doble funcionalidad, la de distribución de espectadores mediante sus aperturas, escaleras y galerías, y por su composición edilicia, la de soportar los empujes, fuerza y peso del resto de la estructura superior. A esta estructura la hemos denominado cuerpo intermedio $^{27}$ a modo de diferenciación de partes internas del anfiteatro, y suele aparecer entre las cáveas a modo de barrera física para evitar los disturbios entre las clases sociales, como en los ejemplos más cercanos de Nimes y Cagliari, tanto en composición como en cronología adrianea, estando situado en Itálica entre la media y summae cavea (Fig. 1). Además, cada cuerpo tendría una serie de galerías interiores abovedadas con fines arquitectónicos para soportar el peso de las partes superiores, estancias y escaleras internas, quedando vestigios de ello en los niveles actualmente conservados. Gracias a esta distribución, finalmente, podemos realizar un nuevo cálculo de su aforo, mediante el cálculo de cada una de las elipses como veremos posteriormente.

${ }^{27}$ Véase la Tesis Doctoral defendida recientemente en 2017: José David Mendoza Álvarez, “Análisis historiográfico del anfiteatro de Itálica" (Tesis doctoral, Universidad de Sevilla, 2017). 


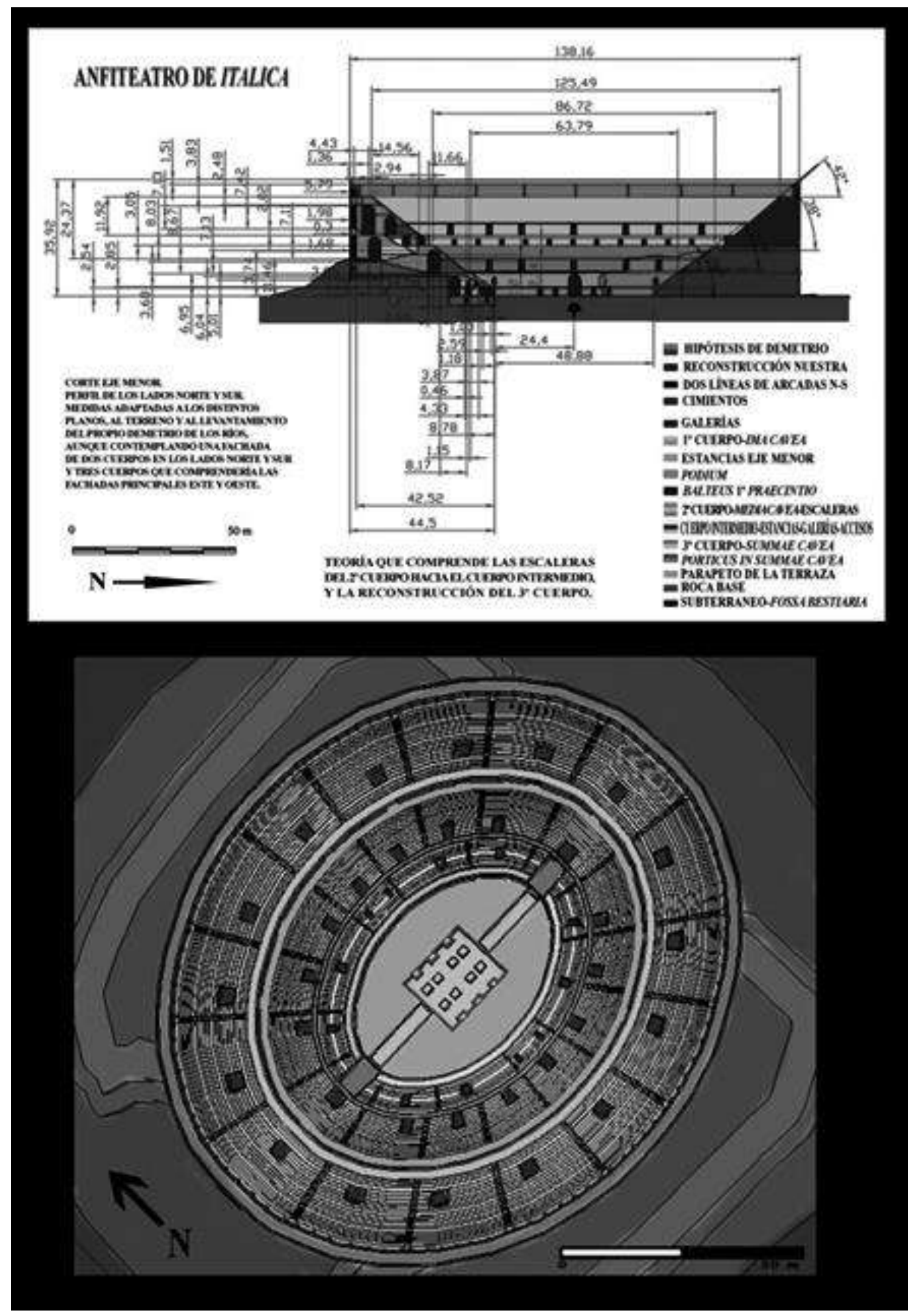

Fig. 1.- Digitalización y restitución del anfiteatro de Itálica según el autor. Arriba, medidas reales en la propuesta de restitución sobre los diseños de Demetrio de los Ríos ${ }^{28}$ en 1862. Abajo, reconstrucción en 3D del anfiteatro, vista en planta.

${ }^{28}$ Demetrio de los Ríos, Memoria arqueológico-descriptiva del anfiteatro de Itálica (Madrid: Imprenta de 
Gran parte del anfiteatro de Itálica fue desmontado tras su abandono, sobre todo despojado de sus mármoles, columnas y rejas metálicas en un primer momento, perdurando su estructura íntegra, que fue colmatada progresivamente con sedimentos del arrastre de materiales al no mantenerse el sistema de cloacas del edificio. Por ello, la colmatación interior fue más elevada que la exterior. La historiografía mantiene que Itálica se redescubrió en el siglo XVI, siendo las ruinas de lo que quedaba conocidas como Taliqa, Campos de Talca y Sevilla la Vieja, pues aunque se la identificase con Itálica, hasta principios del siglo XIX no se estableció por Decreto que la ciudad recuperase su verdadero nombre. Pero debemos matizar la idea del redescubrimiento pues en realidad la ciudad de Itálica nunca se abandonó sino que en una primera etapa con las invasiones, la ciudad se redujo y mantuvo un pequeño núcleo en el que se permitía a una comunidad cristiana custodiar las reliquias sagradas de San Isidoro. Con la Reconquista, sus tierras se repartieron, se construyó el monasterio de San Isidoro del Campo, y sus posesiones fueron administradas por los monjes. A finales del siglo XVI y principios del siglo XVII el pueblo vecino de Santiponce solicitó la ayuda del monasterio para trasladar su caserío el cual había sufrido numerosas riadas debido a las crecidas del río, por lo que éstos le concedieron parte de sus tierras donde hoy día se establece el actual pueblo de Santiponce, el cual se ha fosilizado al urbanismo romano preexistente, por lo que se muestra una nueva prueba de que la ciudad nunca fue abandonada en su totalidad. No ocurrió lo mismo con la ampliación adrianea, la cual sufrió el expolio y destrucción de sus edificios para reutilizar sus materiales constructivos, conservándose tan solo a poca altura algunos restos de las viviendas, parte de las termas mayores, el traianeum a nivel de cimentación y lo que hemos descrito del anfiteatro, todo gracias a la sedimentación de la que venimos hablando, a la que debemos agradecer esta protección natural de los restos de la ciudad pues sin ella, todo hubiese sido extraído para reutilizar sus materiales. Por tanto, el anfiteatro sería desmontado progresivamente tan sólo en sus niveles superiores desde el siglo XVI, quedando reflejado en los textos e ilustraciones las formas que con el paso del tiempo se iba conformando. El problema radicó en ese nivel de colmatación, pues al ir descendiendo, también facilitó el expolio y destrucción del resto del edificio hasta el siglo XIX en el que se intentó poner freno a parte del tercer cuerpo que aún quedaba en pie, aunque sin fortuna.

José Rodríguez, 1862). 
Centrándonos en los textos, documentos e imágenes que describen el edificio, extraemos los autores más importantes que pretendieron mostrar el estado del anfiteatro y se preocuparon en protegerlo, con distinta suerte pues la legislación que se iba conformando desde el siglo XVIII carecía de un cuerpo sancionador para aquellos que atentasen contra el patrimonio de la Nación, hecho que no se subsanó hasta principios del siglo XX con la Ley de Excavaciones de 1911 y su Reglamento de 1912. En 1548, Pedro de Medina ${ }^{29}$ describió los restos de Itálica como "pedazos de edificios muy antiguos", y en particular, los restos del anfiteatro como "un coliseo con muchas puertas o ventanas". El grabador Flamenco Antón Van Den Wyngaerde ${ }^{30}$ dibujó el anfiteatro en 1567 (Fig. 2), añadiendo la leyenda ${ }^{31}$ : “Coliseo de Sebilia La Vechia alrededor tiene 506 pasos”. Esta primera imagen artística no ha sido analizada en la forma que debiera pues tan solo se aprecian restos sin escala, muy colmatados, que parecen estar siendo desmontados. ${ }^{32}$ No obstante, si prestamos atención a los detalles podemos reconocer un cuerpo intermedio, una serie de cunei con sus vomitoria, colmatación de la arena hasta niveles muy elevados y destrucción de la parte superior y externa del edificio. En el dibujo de G. Braum de 1588 parece apreciarse cómo se intenta recrear los niveles superiores muy derruidos, así como un interior donde creemos apreciar el cuerpo intermedio con numerosas entradas. En la imagen posterior de Diego de Cuelvis vemos un edificio representado de forma idílica aunque no por ello deja de presentarnos detalles, ya que apreciamos tanto en el interior como en el exterior, numerosas aperturas, pudiendo referirse las de su interior a los vomitoria o a las puertas del cuerpo intermedio. ${ }^{33}$

A pesar de que el edificio estaba muy condicionado por su derrumbe y desmonte, en el siglo XVI se siguen realizando descripciones del mismo que nos han aportado datos fundamentales para determinar, por ejemplo, la altura de la propia colmatación interior

\footnotetext{
${ }^{29}$ Pedro de Medina, Libro de grandezas y cosas memorables de España (Alcalá de Henares: Biblioteca Nacional de Austria, 1566), 52; De Los Ríos, "El anfiteatro de Itálica...", 388; Rodrigo Amador de los Ríos, Excavaciones en el anfiteatro de Itálica. Memoria de los trabajos practicados en 1915 (Madrid: Revista de Archivos, Bibliotecas y Museos, 1916), 8.

${ }^{30}$ José María Luzón, Sevilla la Vieja. Un paseo histórico por las ruinas de Italica (Sevilla: Fundación Focus-Abengoa, 1999), 25; José Manuel Rodríguez, "Historia de la investigación”, en Ciudades romanas de Hispania 7: Italica-Santiponce. Municipium y Colonia Aelia Augusta Italicensium, ed. Antonio Caballos Rufino (Roma: Erma Di Bretschneider, 2010), 22; José Manuel Rodríguez, "Itálica. La Pompeya Española", en De Pompeya al Nuevo Mundo. La corona española y la arqueología del siglo XVIII. Real Academia de la Historia. Patrimonio Nacional, ed. Martín Almagro y Jorge Maier (Madrid: Real Academia de la Historia, 2012), 127; José Manuel Rodríguez, "Hitos de una historia gráfica del descubrimiento de Itálica", Itálica, revista de arqueología clásica de Andalucía, n. 2 (2012): 16.

${ }^{31}$ Luzón, Sevilla la Vieja..., 27.

${ }^{32}$ Bellido, "Panorama historiográfico...", 40.

${ }^{33}$ Rodríguez, "Itálica. La Pompeya Española...", 128; Rodríguez, "Hitos de una historia gráfica...”, 16.
} 
que presentaba el anfiteatro y que ha pasado desapercibida por todos los investigadores. Hasta el siglo XIX no se comenzó a vaciar el interior del edificio para las obras de la carretera que conducía a Badajoz, la cual dividió en dos la antigua ciudad o Vetus Urbs condicionando el trazado urbanístico actual y distribuyendo la ciudad de Santiponce en dos cerros inexistentes durante el periodo romano. A pesar de las denuncias que se realizaron para proteger a las ruinas, las obras continuaron y mermaron el anfiteatro hasta configurarlo prácticamente en la forma que tiene actualmente. Por ello, en los siglos XVI y XVII el panorama que presentaba el anfiteatro era tan caótico que no permitía distinguir su trazado y forma correctamente, llegándose a dudar sobre si era un teatro o anfiteatro como comentó Ambrosio de Morales ${ }^{34}$ en 1575. A finales del siglo XVI aparece en escena Rodrigo Caro, testigo de primera mano del traslado del caserío de Santiponce al lugar donde hoy lo conocemos. Pero no sería hasta el siglo XVII cuando R. Caro identificase las ruinas conocidas como "Sevilla la Vieja" con Itálica. ${ }^{35}$ Recoge del anfiteatro ${ }^{36}$ que era una "obra insigne destruido en la mayor parte, todavía conserva la forma circular aunque se llega al óvalo con 65 pasos de diámetro". ${ }^{37}$ Ahí presentamos la primera prueba más fiable de la existencia de una gran colmatación del interior de la arena hasta una altura calculada por nosotros que alcanzaría entre los 15 y 18 metros, no sólo al convertir los pasos de la época en metros actuales, sino al tener en cuenta la descripción de R. Caro que realiza sobre un posible podium y enumerando veinte filas de gradas sobre el mismo sin praecintio, hecho que no podemos entender que se tratase del verdadero podium pues éste presentaría a continuación la ima cavea con ocho filas de gradas, y sería desenterrado por Demetrio de los Ríos en la década de los años sesenta del siglo XIX.

\footnotetext{
${ }^{34}$ Ambrosio de Morales, Las angigvedades de las civdades de España (Alcalá de Henares: Real Academia de la Historia, 1575), 83-84.

${ }^{35}$ García y Bellido, Andalucía Monumental..., 63.

${ }^{36}$ Rodrigo Caro, Antigüedades y principado de la ilustrísima ciudad de Sevilla y Chorographía de su convento jurídico, o antigua cancillería, dirigida al excelentísimo señor Don Gaspar de Guzmán, Conde Duque de Sanlúcar la Mayor (Sevilla: Enrique Bergali, 1634), 110.

${ }^{37}$ Caro, Antigüedades y principado de la ilustrísima ciudad de Sevilla..., 110.
} 


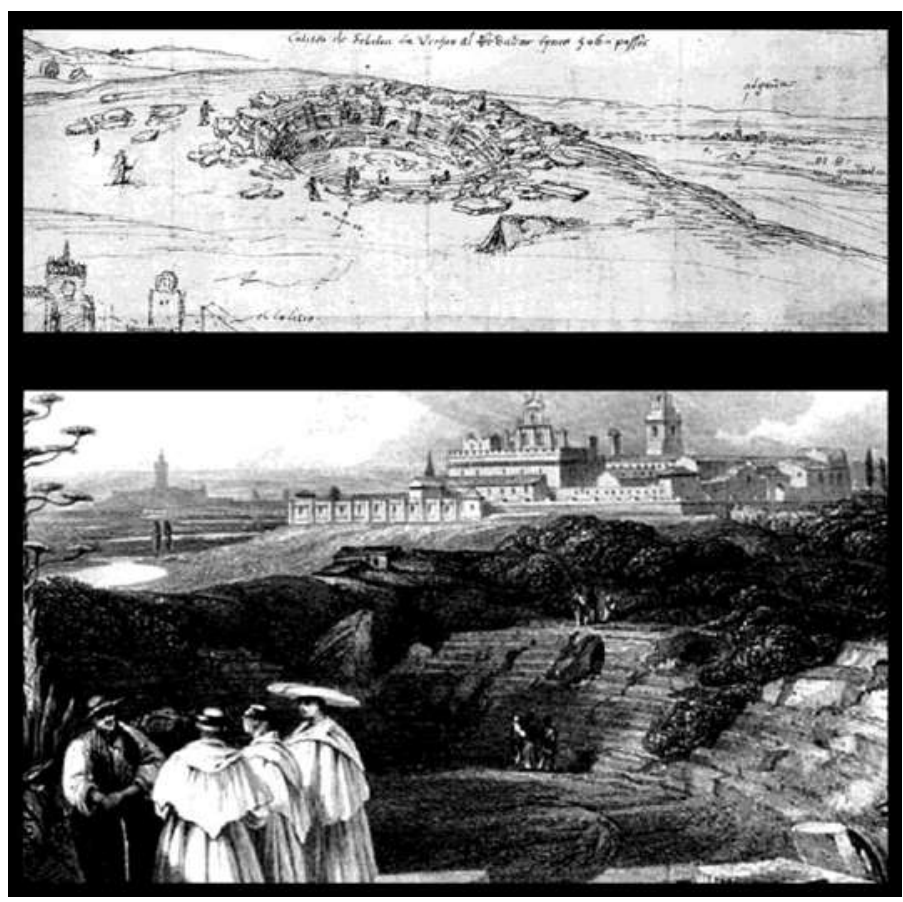

Fig. 2.- Ilustración del anfiteatro de Itálica según Wyngaerde ${ }^{38}$, en la parte superior. Dibujo de David Robert, en la parte inferior, de 1835 donde se observa el detalle del cuerpo intermedio colmatado hasta su nivel superior, en el lugar donde los hombres del interior del edificio conversan. ${ }^{39}$

Los ejes máximos del anfiteatro tanto para J. C. Golvín como para otros autores ${ }^{40}$, en cuanto a dimensiones se refiere, se establecen en 156,5×134 m mientras que los ejes que conformarían la arena comprenderían los 71,5x49 m. A su vez, M. Wilson Jones ${ }^{41}$ establece unas diferencias mínimas según su estudio geométrico, pues comprende unos ejes máximos de 153x128,25 m y unos mínimos de 70,7x45,95 m. Esto ha sido una constante con la que nos hemos encontrado al determinar las medidas de algunos de los anfiteatros analizados donde comprobamos que los autores no logran ponerse de acuerdo para establecer unas medidas reales que en ocasiones varían algunos metros, como en el caso del Coliseo. En nuestro caso, los cálculos de R. Caro nos indican unos 65 pasos que corresponden a 325 pies lo cuales a su vez, para un pie de 0,29 m nos da una cifra de 94,25 m, que si lo aplicamos a la descripción del edificio del momento, llegamos a la conclusión que estaría colmatado a una altura estimada entre 15 y 18 m, correspondiente

\footnotetext{
38 José Beltrán Fortes y José Manuel Rodríguez, Itálica: espacios de culto en el anfiteatro (Sevilla: Universidad de Sevilla, 2004), 36; Bellido, "Panorama historiográfico...", 40; Caballos (ed.), Ciudades romanas de Hispania..., 22.

${ }^{39}$ Alicia Canto, "La Vetus Urbs de Italica, quince años después: La planta hipodámica de D. Demetrio de los Ríos, y otras novedades", CuPAUAM, n. 25 (1999): 187; Caballos (ed.), Ciudades romanas de Hispania..., 73.

${ }^{40}$ García, El anfiteatro..., 13; Golvín, L ‘Amphitheatre Romain ..., 200.

${ }^{41}$ Wilson, "Designin Amphitheatres...", 442.
} 
valga la casualidad al final de la media cavea conocida en la actualidad, lugar desde donde se erigiría el cuerpo intermedio de distribución de peso del resto del edificio, conformando un aspecto similar al podium, con el que sería confundido por estos autores desde R. Caro, de la misma forma que hemos podido ver y comparar en otros anfiteatros como el de Nimes o Cagliari.

Pero sería impropio hablar del término casualidad para la ciencia, pudiéndose utilizar para un lenguaje cotidiano sobre las dimensiones del edificio y su extraordinaria correspondencia como hemos comentado. Posteriormente veremos las plantas que hemos consultado de los planos oficiales que se fueron confeccionando desde principios del siglo XVIII y coinciden en numerosos puntos con los datos que se tienen respecto a las longitudes de las cáveas de los niveles superiores, por lo que en ningún momento debemos entender aquellos levantamientos como fruto de la casualidad, sino como datos técnicos específicos y meramente científicos que se adaptan a las dimensiones reales del edificio.

Con todo ello, hemos podido establecer una primera correspondencia entre el texto de R. Caro y la imagen de A. Wyngaerden que de forma artística nos representaría el tercer cuerpo muy colmatado. La segunda correspondencia la extraemos en el siglo XVIII del texto de Enrique Flórez y las plantas del edificio de Manuel Martí y las de Juan de Espinar, además de los grabados artísticos que fueron realizándose desde este momento con más lujo de detalles. En esta ocasión, E. Flórez contabiliza unas 15 filas de gradas que arrancan desde el podium y deben entenderse como parte de las correspondientes del tercer cuerpo, el mismo que vio R. Caro, el cual estaría siendo desmontado lenta y paulatinamente, y no se debe intentar demostrar que E. Flórez se referiría a la media cavea actual, debiendo indicar que hemos contabilizado in situ unas 14 filas de gradas comprobando como en la parte superior de la bóveda aún conservada, se extendería una planicie la cual debía corresponder al suelo del cuerpo intermedio. Este error ha condicionado toda la investigación posterior y nos ha permitido establecer nuestras hipótesis sobre el cuerpo intermedio y la tercera cavea. ${ }^{42}$ Además de ello, E. Flórez habla de bóvedas y la existencia de 16 puertas distribuidas en 8 a cada lado del eje mayor ${ }^{43}$, lo que debemos interpretar que los restos del tercer graderío situado sobre las puertas principales al este y oeste, al estar confeccionado sobre espacios abovedados y ser

\footnotetext{
${ }^{42}$ Enrique Flórez, España Sagrada. Teatro Geográfico Histórico de la Iglesia de España. Tomo XII: De las Iglesias sufragáneas antiguas de Sevilla: Egabro, Elepla, Eliberi, Italica, Málaga y Tucci (Madrid: Fortanet, 1776), 234; De Los Ríos, "El anfiteatro de Itálica...", 391.

${ }^{43}$ Flórez, España Sagrada..., 235.
} 
desmontados, junto a la acción de la dilatación del terreno por estar sobre una vaguada y sobre todo por el gran terremoto de Lisboa de mediados del siglo XVIII, la fuerza de la gravedad haría que las moles de opus caementicium del que estaba compuesto las gradas, cayesen de la forma similar a cómo podemos ver hoy los fragmentos de la segunda cavea, lo que induce nuevamente al error al tomar los grabados del momento y querer ver que se representaban el segundo cuerpo.

Enrique Flórez habla de 291 pies castellanos para su eje mayor ${ }^{44}$, lo que siguiendo el mismo razonamiento de $\mathrm{R}$. Caro, y atendiendo a la medida del pie castellano, algo más pequeño que el romano, obtenemos unos $81,5 \mathrm{~m}$. De ello podemos deducir que en tiempos de E. Flórez, ha disminuido algo la colmatación existente en el interior de la arena. En esta ocasión, acompañamos las referencias textuales con las plantas realizadas ya en el siglo XVIII las cuales digitalizamos y superpusimos con la sorpresa que coincidían con el edificio italicense en modulación conforme se levantaba en altura. Así mismo, presentamos una nueva planta realizada por los topógrafos militares y recogida en el Archivo Histórico Militar ${ }^{45}$ (AHM en adelante), la cual hemos determinado que correspondería al cuerpo intermedio. Esto viene a significar que la medida del largo de la cavea que presentarían las plantas consultadas, las de M. Martí, E. Flórez y AHM, se reducirían respecto al distinto nivel de altura al cual correspondería, y serían muy diferentes a las que trazó Demetrio de los Ríos ya en el siglo XIX, la cual hemos identificado como perteneciente al segundo cuerpo gracias a los detalles que la obra de Demetrio nos ofrece y hemos podido comprobar (Fig. 3).

\footnotetext{
${ }^{44}$ Flórez, España Sagrada..., 236.

45 Jesús Salas Álvarez, "La recuperación del patrimonio arqueológico de Andalucía durante la Ilustración (1736-1808)" (Tesis doctoral, Universidad de Sevilla, 2004), 682.
} 


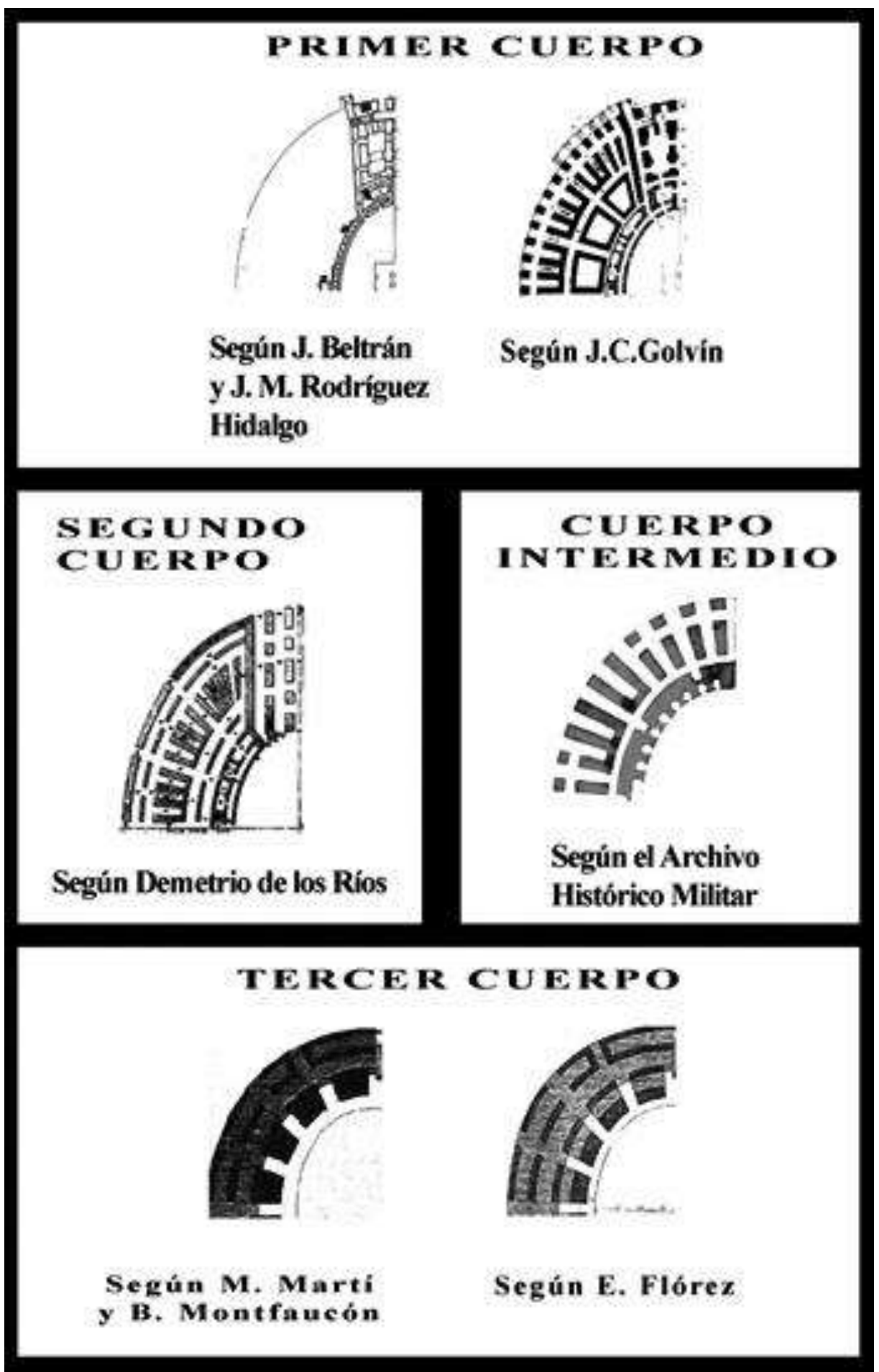

Fig. 3.- Plantas para cada nivel del anfiteatro según el autor. Para el primer cuerpo las realizadas por J. C. Golvín ${ }^{46}$ en 1988 y por J. Beltrán y J. M. Rodríguez Hidalgo ${ }^{47}$ en 2004; para el segundo cuerpo la establecida por D. de los Ríos ${ }^{48}$ en 1862; para el cuerpo intermedio la del AHM en el siglo XVIII; y para el tercer cuerpo las dispuestas por M. Martí y B. de Montfaucón y la de E. Flórez. ${ }^{49}$

\footnotetext{
${ }^{46}$ Golvín, L `Amphitheatre Romain...

${ }^{47}$ Beltrán y Rodríguez, Itálica: espacios de culto en el anfiteatro....

${ }^{48}$ De Los Ríos, Memoria arqueológico-descriptiva del anfiteatro de Italica...

${ }^{49}$ Luzón, Sevilla la Vieja..., 35-37; Beltrán y Rodríguez, Itálica: espacios de culto en el anfiteatro....37; Bellido, "Panorama historiográfico...", 45; Salas, "La recuperación del patrimonio...”, 682; Jesús Salas
} 
Francisco Pérez Bayer junto al dibujante Asencio Juliá, a finales del siglo XVIII visitaron Itálica y su anfiteatro, legándonos una nueva representación del anfiteatro en la cual observamos nuevos detalles que hemos comparado con la planta del $\mathrm{AHM}^{50}$, con lo que apreciamos nuevos datos relevantes para nuestras hipótesis de restitución. En el dibujo de Asencio Juliá se contabiliza al menos hasta 14 filas de gradas, en el que tenemos que detallar que aunque sea una representación artística, el dibujante plasmaría los detalles que apreció de un edificio que mantenía en pie su tercer cuerpo, pues de lo contrario, si hubiese observado lo que se cree de los cuerpos actuales, lo habría hecho tal y como lo hubiese contemplado. El detalle lo marcamos en primer lugar en los lados este y oeste que presentan una destrucción por un momento lógica al tener en cuenta que el edificio se conformaría en parte sobre dos cerros y habría canalizado un pequeño arroyo, por lo que el problema de los terremotos y de las arcillas expansivas que sufre la zona, provocaría la dilatación y contracción del terreno al paso del tiempo y los consiguientes derrumbes. El segundo detalle más importante es el de la colmatación pues parece que se acerca a una praecintio que da acceso a los vomitoria, contemplándose cómo bajo ella continúa el graderío. En este momento debemos prestar atención al perfil realizado por el AHM donde contemplamos lo que se ha creído el podium y nosotros hemos interpretado como cuerpo intermedio sobre el que se erige la tercera cavea. Son las primeras gradas de este perfil lo que se representa en el dibujo de A. Juliá pues vemos cómo en el perfil se representa una galería interna con un acceso escalonado hacia el graderío, lo que demostraría que los vomitoria se encontrarían unas gradas por encima del cuerpo intermedio, el cual aparece en planta representado con muchas estancias, motivo a tener en cuenta en los siguientes grabados.

Un detalle muy significativo fue el de los ingenieros militares del siglo XVIII que pretendieron restituir el anfiteatro mediante la utilización de distintos colores para su plano pues pretendían atender a las premisas que se establecieron en el momento de recalcar las partes conservadas a una tinta de la que se pretendía restituir a otro tono y grosor de línea. De esta forma nos han proporcionado un perfil muy ajustado a la realidad de lo conservado en aquél preciso momento, en el cual contamos veintiocho filas de grada

Álvarez, "El viaje arqueológico a Andalucía y Portugal de Francisco Pérez Bayer”, SPAL, n. 16 (2007): 20; Caballos (ed.), Ciudades romanas de Hispania..., 24.

${ }^{50}$ Salas, "La recuperación del patrimonio...", 682; Alicia León Gómez, Imágenes arqueológicas de la España ilustrada. El teatro romano de Sagunto en el siglo XVIII (Sevilla: Universidad de Sevilla, 2006), 37. 
que consideramos excesivas y las hemos corregido según nuestra digitalización, que sigue el modelo del anfiteatro de Nimes en cuanto a estructura interna al contar éste con un cuerpo intermedio al que le sigue unas veinte filas de gradas, que curiosamente son las descritas por R. Caro para el caso italicense, y hemos recalculado digitalmente con la sorprendente coincidencia de las medidas que nos presenta los planos analizados, proporcionándonos el espacio suficiente para establecer un porticus in summae cavea relativamente amplio gracias a incluir el trazado de la escalera perimetral por el interior del edificio como nos indicaba Demetrio de los Ríos. ${ }^{51}$

Alexandre Laborde a principios del siglo XIX, nos deja un nuevo detalle que refuerza nuestra hipótesis, pues dibuja un edificio muy destruido y colmatado en una visión desde el interior de una bóveda. Al fondo recrea lo que hemos estado denominando como el cuerpo intermedio y unos vomitoria con una serie de filas de gradas iguales a las que vemos en el perfil del $\mathrm{AHM}^{52}$, es decir, que presenta un acceso a varias filas de gradas que arrancan desde el cuerpo intermedio, no pudiéndose nunca confundir con los vomitoria que en la actualidad contemplamos para el segundo cuerpo, pues éstos acceden directamente a la praecintio que lo separa de la primera cávea. De la misma forma lo vemos en el dibujo de J. Taylor de 1832, momento en el que el edificio estaba siendo reducido a escombros. ${ }^{53}$ En esta ocasión vemos en primer plano unos jinetes sobre una arena muy colmatada, lo que no deja de mostrarnos el detalle del cuerpo intermedio gracias a uno de los vanos representados, al mismo tiempo que unas filas de gradas antes de acceder a los vomitoria. Poco tiempo después, en 1835, David Roberts ${ }^{54}$ nos deja un nuevo detalle en su representación del anfiteatro (Fig. 2) pues distinguimos el cuerpo intermedio marcado por una línea sobre la que varios hombres parecen dialogar al fondo en su dibujo. Sobre el mismo se erigen varias filas de gradas antes de llegar a los vomitoria. Esta imagen sería la que vería Demetrio de los Ríos en su primer contacto con el anfiteatro durante la década de los años cuarenta del siglo XIX. Demetrio dejó una acuarela del edificio con el detalle de las aperturas centrales del cuerpo intermedio, que se corresponden a las que detectamos en la planta del AHM. Si tenemos en cuenta las

\footnotetext{
${ }^{51}$ De Los Ríos, Memoria arqueológico-descriptiva..., 30.

52 Juan Carriazo, "Estado actual de las excavaciones de Itálica: La manzana del gimnasio", Anuario del Cuerpo Facultativo de Archiveros, Bibliotecarios y Arqueólogos, n. 3 (1935): 31; Beltrán y Rodríguez, Itálica: espacios de culto en el anfiteatro...", 36; Salas, "La recuperación del patrimonio...", 223.

${ }^{53}$ Pilar León Alonso, "Las ruinas de Itálica: una estampa arqueológica de prestigio", en La Antigüedad como argumento. Historiografía de Arqueología e Historia Antigua en Andalucía, eds. José Beltrán y Fernando Gascó (Sevilla: Fundación Instituto Gallego, 1993), 51.

${ }^{54}$ Canto, La Vetus Urbs de Itálica..., 187; Caballos, Ciudades romanas de Hispania ..., 73.
} 
medidas actuales del edificio, respecto a la altura de las gradas, esta colmatación representada corresponde a 18 metros hasta la parte superior del cuerpo intermedio, el cual está descrito con unas dimensiones de 2,9x3 m, que correspondería con los 15 metros donde termina en la actualidad la media cavea, medidos desde el nivel de la arena, pues nunca hemos hecho referencia a metros sobre el nivel del mar como ya señalamos con anterioridad.

Aún a mediados del siglo XIX, el anfiteatro tenía en pie parte de su tercera cávea que fue desmontada por el cuerpo de ingenieros encargado de las reparaciones de la carretera de Extremadura, polémico hecho que desde pronto fue denunciado, tomando gran repercusión mediática desde 1855 hasta 1860, denunciado con insistencia por Demetrio de los Ríos ${ }^{55}$. Además de la colmatación, Demetrio se enfrentó ya como director de las excavaciones desde 1860, a un edificio muy mermado por todo el daño sufrido para la extracción de su material, desapareciendo por completo lo que restaba del tercer nivel y desmoronándose el segundo tal y como había indicado el propio Demetrio cuando el cuerpo de ingenieros comenzó a vaciar las bóvedas y estancias que encontraban ${ }^{56}$. El propio Demetrio llegó a decir que si se vaciaban las bóvedas, éstas se desplomarían por su mal estado de conservación, hecho que sucedió, siendo necesario que se apuntalasen muchas de ellas, llegando hasta nosotros parte del segundo cuerpo en el sector oriental, que sería sobre el que Demetrio centró sus investigaciones, hecho que venimos manteniendo en nuestras hipótesis pues las reconstrucciones que hizo contemplaba la escalera perimetral por el interior del conjunto, y esto se puede entender solo si vemos una planta correspondiente con el segundo cuerpo a la que debemos añadir que nuestra digitalización del plano de Demetrio de los Ríos, corresponde al milímetro con los planos más recientes del anfiteatro. Por ese motivo, la interpretación que se le da a la planta de Demetrio es que correspondería al segundo cuerpo, pues el detalle lo vemos en las dimensiones continuas del perímetro de la elipse que se adapta al terreno y el ángulo de las galerías que se presentan paralelas a la galería principal siendo los niveles actuales diferentes, conformados por dos galerías radiales inclinadas con respecto al pasillo principal del eje mayor, además de poseer estancias a ambos lados del mismo, detalle que

\footnotetext{
55 Véase http://www.cervantesvirtual.com/portales/san_juan_de_la_cruz/obra/oficio-de-traslado-aldirector-general-de-agricultura-industria-y-comercio-en-el-que-se-describe-el-nuevo-destrozo-efectuadoen-distintos-lugares-de-las-ruinas-de-italica-se-pide-a-la-real-academia-de-la-historia-eleve-su-queja-algobierno-y-se-proponen-algunas-mediadas-para-su-conservacion/

${ }^{56}$ Véase http://www.cervantesvirtual.com/obra/litografia-de-la-planta-y-seccion-del-anfiteatro-de-italica/
} 
no se contempla en la planta de Demetrio, ni en los restos conservados comentados con anterioridad.

De esta forma podemos determinar la configuración de la fachada mediante pilares con columnas adosadas en la forma que actualmente lo distinguimos, pero además se configuraría con una serie de columnas confeccionando un pórtico monumental propio de un edificio de este tipo y del gusto de la edilicia adrianea. Para demostrar nuestra hipótesis debemos indicar que durante las excavaciones de la fachada a principios del siglo XX se localizó un capitel corintio labrado en todas sus caras, lo que descartaría que fuese realizado con el fin de embutirse en los pilares a modo de semicolumna, y de la misma forma en las excavaciones de la fosa bestiaria se halló un tambor de columna estriado. Un estudio arquitectónico avalaría tal hipótesis al demostrar como necesario la colocación de columnas en ese sector para evitar el hundimiento del resto del edificio. Este hecho sería argumentado además con las descripciones de Demetrio respecto a la fachada y a la escalera perimetral. ${ }^{57}$ De esta forma, vemos el paralelo más inmediato de fachada en el anfiteatro de Cagliari.

Respecto al cálculo de su aforo, debemos indicar que ha sido posible gracias a determinar en primer lugar la forma geométrica de la elipse para el trazado del diseño del anfiteatro, y descartar el óvalo por no presentar soluciones matemáticas capaces de sortear los desniveles del terreno. Por lo general se establece que un anfiteatro triplicaba el aforo de la población en la que se establece, con el fin de acoger espectadores venidos de otros $\operatorname{lugares}^{58}$, siendo para Itálica estimada una población entre 8.000-10.000 habitantes ${ }^{59}$ mientras que se creía que el aforo rondaba entre 20.000 y 25.000 espectadores $^{60}$, hecho que hemos recalculado conforme a nuestras propuestas de restitución edilicia y tomando como media para cada persona pie y medio ${ }^{61}(0,45 \mathrm{~m})$, dándonos como resultado una cifra

\footnotetext{
${ }^{57}$ De Los Ríos, Memoria arqueológico-descriptiva..., 24.

${ }^{58}$ Ceballos, "Geografía y cronología de los ludi...", 442.

${ }^{59}$ Blázquez, "La Itálica de Trajano y Adriano...", 312; Pellicer, "Panorama de la arqueología...", 188.

${ }^{60}$ García, Andalucía Monumental..., 120; José María Blázquez, "El urbanismo en Occidente”, en Homenaje a Samuel de los Santos (Albacete: Instituto de Estudios Albacetenses, 1988), 181; Mary T. Boatwright, "Itálica y la magnificencia urbana de Adriano", en Itálica MMCC. Actas de las jornadas del 2200 Aniversario de la Fundación de Itálica. Sevilla, 8-11 noviembre 1994, eds. Antonio Caballos Rufino Pilar León (Sevilla: Consejería de cultura, empresa pública de Gestión de programas, 1997), 220; Ceballos y Ceballos, "Los espectáculos del anfiteatro...", 59; Hidalgo, Anfiteatros..., 223; Bellido, "Panorama historiográfico...", 35.

61 Alicia Canto, "Némesis y la localización del circo de Italica", BSAA, n. 52 (1986): 52; Golvín, L `Amphitheatre Romain..., 387; Antonio Almagro y Martín Almagro-Gorbea, "El anfiteatro de Segobriga", en Bimilenario del anfiteatro Romano de Mérida. Coloquio Internacional el anfiteatro en la Hispania Romana. Mérida, 26-28 de noviembre de 1992, coord. José María Álvarez Martínez y Juan Javier Enríquez Navascués (Mérida: Junta de Extremadura, 1994), 153.
} 
algo mayor, como veremos a continuación. Esta gran capacidad demostraba la importancia que tendría Itálica a la hora de ofrecer juegos, disponiéndose para acoger grandes multitudes que sin duda vendrían de poblaciones cercanas.

Hemos realizado una serie de cálculos que determinan con gran precisión el número de espectadores que pudo llegar a tener el anfiteatro de Itálica. En primer lugar hemos digitalizado las medidas completas de la planta del anfiteatro, con la restitución ideal según nuestras hipótesis. En segundo lugar, hemos establecido, siguiendo nuestras hipótesis, y como hemos comentado con anterioridad, las elipses que conformarían cada sector del edificio, desde el podium hasta la terraza, determinando todas las elipses de cada una de sus filas de gradas. Una vez obtenidas todas las elipses, calculamos el perímetro de cada una de ellas según la fórmula siguiente como ecuación más aproximada a la obtención de una elipse:

$$
\mathrm{P}=2 \pi \sqrt{\left(a^{2}+b^{2}\right) / 2}
$$

Donde $P$ es el Perímetro; $a$ es el radio menor; $b$ es el radio del eje mayor.

Seguidamente, calculamos cada uno de los radios menores y mayores y le aplicamos la fórmula. Una vez obtenido una cifra total, restamos los espacios de las escalinatas que separan todos los cunei, las de todos los vomitoria del segundo y tercer cuerpo, y la de los accesos del primer cuerpo, dependiendo de las filas de gradas a las que se le debían de aplicar, pues los vomitoria y accesos correspondían a un número limitado de filas mientras que las escalinatas se debían aplicar a todas las gradas del segundo y tercer cuerpo, hecho que nos reservamos un pequeño margen de error, respecto a algún otro vano que pudiese tener del cual no tengamos constancia, lo que nos hace establecer una cifra aproximada y no absoluta. Después de realizar este cálculo, dividimos el total por pie y medio que se establece para una plaza estándar, que establecemos en 0,45 metros.

Gracias a estos cálculos, y teniéndose en cuenta los espacios que habría que restar, el aforo se eleva a 24589 plazas. Pero nuestra investigación no se detiene en este punto, pues si analizamos lo establecido por Demetrio, obtiene un total de 21300 espectadores, indicando que se podría aumentar a 25000 teniéndose en cuenta el espacio que él no se aventuró en restituir. ${ }^{62}$ Esta cifra ha sido copiada por muchos autores, como hemos visto, e incluso ampliada sin criterio alguno. Nosotros hemos propuesto un cálculo lógico y lo

\footnotetext{
${ }^{62}$ De Los Ríos, Memoria arqueológico-descriptiva..., 82.
} 
hemos demostrado, por lo que podemos asegurar un número, aunque no exacto debido a lo comentado con anterioridad, si aproximado con un margen de error de \pm 100 espectadores. Ahora bien, si añadimos lo calculado por Demetrio ${ }^{63}$ para los espectadores que podían ocupar el podium, los excuneatos, y los que se establecerían en la terraza, cuyo número se eleva a 2980, la cifra nuestra aumentaría hasta los 27569 espectadores. Pero ahí no queda la cosa, pues si Demetrio no tuvo en cuenta el cuerpo intermedio, el cual se compone de forma similar al podium, aunque con una amplitud mayor, debemos estimar al menos el mismo número que Demetrio propuso para el podium, que sumándolo a nuestro cálculo supondrían un total de 27829 espectadores con \pm 100 de margen de error. Resumiendo este apunte, no podemos redondear cifras pues se alejaría de la realidad, por lo que fijaremos esta cifra como la estimada según nuestra investigación, adaptada a las hipótesis de restitución y nueva configuración del anfiteatro, en el que todas las medidas se presentan digitalizadas.

\section{Conclusiones}

A lo largo de esta investigación, hemos comentado cuestiones relacionadas con el anfiteatro de Itálica para cumplir con el objetivo principal planteado de proponer su restitución. Para ello, ha sido necesario realizar un minucioso estudio historiográfico, histórico y arqueológico, en el que hemos recopilado textos, archivos, fuentes históricas e ilustraciones y planos oficiales en las que nos hemos centrado para determinar los aspectos que habían pasado desapercibido hasta la fecha. De esta manera, hemos establecido una nueva estructura para el anfiteatro italicense (Fig. 4), y por ende para el resto de anfiteatros analizados, que denominamos cuerpo intermedio y presenta un diseño estructural establecido para soportar el peso del resto de las partes superiores del edificio, gracias a su arquitectura mediante el uso de los arcos y las bóvedas, y también como distribuidor de espectadores a las distintas cáveas, en este caso al encontrarse entre la segunda y tercera, de distribución de espectadores a ellas.

\footnotetext{
${ }^{63}$ De Los Ríos, Memoria arqueológico-descriptiva ..., 82.
} 


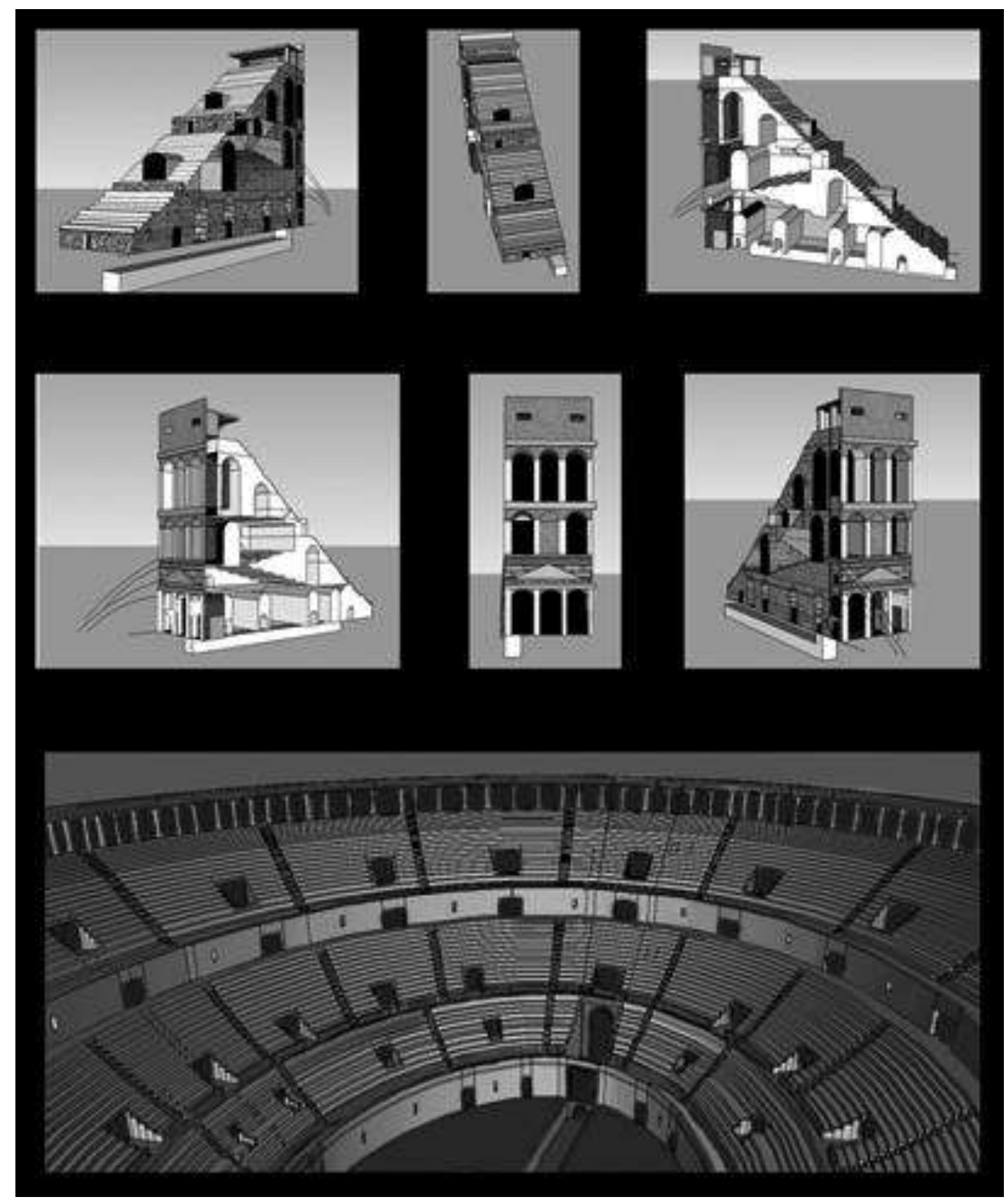

Fig. 4.- Nueva propuesta de restitución del anfiteatro de Itálica según el autor.

Por tanto, el edificio mantuvo parte del tercer cuerpo hasta mediados del siglo XIX, en el que será destruido hasta configurar los aspectos que observamos hoy día. Respecto a su planta, hemos procedido a determinarla como elíptica al comprobar cómo esta figura geométrica se adapta a los desniveles del terreno. No obstante, para cada nivel de altura hemos podido establecer una planta oficial que, desde el siglo XVIII se había configurado conforme a los niveles que en cada momento se detectaba gracias a la colmatación que sufría el edificio. Por ello, hasta que no fue excavado completamente, no se entendió una planta correcta para cada cuerpo, y a pesar de ello, se mantiene que 
los levantamientos que se realizaron a mediados del siglo XIX por Demetrio de los Ríos correspondían con el edificio tal y como lo vemos en la actualidad, sin contar con la crítica que hemos desarrollado a lo largo del texto sobre los condicionantes a los que se enfrentó Demetrio, sobre todo por el nivel de sedimentación que el interior del edificio presentaba. No obstante, hemos determinado las siguientes plantas para cada cuerpo, siendo la de J. C. Golvín de 1988 y la realizada por J. Beltrán y J. M. Rodríguez Hidalgo en 2004 las que más se aproximan al primer nivel; la de Demetrio de los Ríos de 1862 para el segundo cuerpo; la del AHM para el cuerpo intermedio; y las de M. Martí y B. Montfaucón en 1711 y E. Flórez de 1776 para el tercer cuerpo ${ }^{64}$ (Fig. 3).

Esta distribución de plantas ha contribuido con la configuración externa del edificio, el cual presenta tres cuerpos de arcadas para los sectores este y oeste y dos para las partes norte y sur, al apoyar parte de su graderío en dos cerros. Todo ello cerrado por un cuerpo de ático. Pero no debemos considerar el edificio como una serie de sucesiones de arcadas abiertas sino que en su diseño, al configurarse la escalera perimetral por el interior del conjunto, se intercaló arcadas cegadas con aperturas abiertas, tanto de iluminación como de accesos según los niveles, alejándose de la imagen que podamos tener de otros edificios como el Coliseo. Esta disposición nos permite establecer la altura total del edificio en 35,92 m frente a los 22,46 m que dispuso Demetrio de los Ríos en un análisis que él mismo indicó que estaba incompleto. ${ }^{65}$ Además, la forma geométrica elíptica nos ha permitido establecer un aforo muy aproximado que se eleva a 27.829 espectadores. Un último apunte lo marcamos en el puesto que ocuparía el anfiteatro de Itálica en el conjunto de anfiteatros del imperio analizados, pues se establece como el cuarto en el ranking de los mayores edificios y el primero de la Península Ibérica.

Para terminar, podemos establecer de forma general que los anfiteatros fueron considerados como las construcciones más emblemáticas de los romanos, simbolizadas por su gran habilidad en ingeniería y arquitectura, con una gran connotación religiosa y militar. ${ }^{66}$ Por ello, el edificio italicense muestra parecidos en numerosos anfiteatros que señalamos como resultado de nuestra investigación en la que hemos tendido que considerar la edilicia adrianea para establecer los mejores ejemplos ${ }^{67}$, donde será Nimes

\footnotetext{
${ }^{64}$ Luzón, Sevilla la Vieja..., 35-37; Beltrán y Rodríguez, Itálica: espacios de culto..., 37; Bellido, "Panorama historiográfico...", 45; Salas, "La recuperación del patrimonio...", 682; Salas, "El viaje arqueológico...", 20; Caballos, Ciudades romanas de Hispania ..., 24.

65 De Los Ríos, Memoria arqueológico-descriptiva..., 115-116.

${ }^{66}$ Wilson, "Designin Amphitheatres...", 391.

67 José María Solana y Luis Sagredo San Eustaquio, "La política edilicia viaria en Hispania durante el reinado de Adriano", HAnt, n. 30 (2006): 35; Adembri Benedetta, Villa Adriana. Guida (Roma: Electra,
} 
el que conformaría un gran paralelo respecto a la estructura interna del edificio. ${ }^{68}$ No obstante, también encontramos el edificio de Cagliari $^{69}$ que presenta no solo una fachada como la que hemos dispuesto para el de Itálica, sino que el mismo se ubica entre montañas, al tiempo que dispone de un cuerpo intermedio y misma cronología. Debemos señalar, que el modelo fundamental para ello siempre ha sido el Coliseo.$^{70}$ No obstante, otros edificios que se muestran muy similares al italicense son los de Carthago Nova ${ }^{71}$; Tarraco $^{72}$; Emporiom ${ }^{73}$; Segobriga ${ }^{74}$; Emerita Augusta, determinado como estructura hueca por Golvín ${ }^{75}$ aunque adaptado a la topografía ${ }^{76}$; Trier con su peculiar construcción en medio de la muralla en su eje menor este oeste, mientras que al norte presentaría tres niveles de arcadas en su puerta principal ${ }^{77}$; o el de Villavieja, en Almería, un pequeño anfiteatro con partes del mismo excavadas en las rocas. ${ }^{78}$

\section{Bibliografía}

Abascal Palazón, Juan Manuel y Urbano Espinosa Ruiz. La ciudad hispano-romana. Logroño: Privilegio y Poder, 1989.

2000), 13 .

${ }^{68}$ De Los Ríos, Memoria arqueológico-descriptiva..., 31; Inmaculada Carrasco Gómez y Alejandro Jiménez Hernández, "A cerca de los edificios de espectáculos en Colonia Augusta Firma Astigi (Écija, Sevilla)", Romula, n. 7 (2008): 34

${ }^{69}$ Mauro Dadea, L`anfiteatro romano di Cagliari (Sassari: Carlo Delfino, 2006), 34.

${ }^{70}$ Beltrán, Lo mejor del Arte Romano..., 29; Domingo Plácido Suárez, "Leyes municipales y símbolos del poder: los fundamentos sociales de la dinastía Flavia", Memorias de Historia Antigua, n. 23-24 (20022003): 13; Hidalgo, “Anfiteatros...," 223.

${ }^{71}$ José Pérez Ballester, Pedro San Martín y Carmen Berrocal, "El anfiteatro romano de Cartagena (19671992)", en Bimilenario del anfiteatro Romano de Mérida. Coloquio Internacional el anfiteatro en la Hispania Romana. Mérida, 26-28 de noviembre de 1992, coord. José María Álvarez Martínez y Juan Javier Enríquez Navascués (Mérida: Junta de Extremadura, 1994), 110-111; Muñoz, El proyecto romano..., 323. 72 Xavier Dupré, "El anfiteatro de Tarraco", en Bimilenario del anfiteatro Romano de Mérida. Coloquio Internacional el anfiteatro en la Hispania Romana. Mérida, 26-28 de noviembre de 1992, coord. José María Álvarez Martínez y Juan Javier Enríquez Navascués (Mérida: Junta de Extremadura, 1994), 80.

${ }^{73}$ Golvín, L`Amphitheatre Romain..., 121; Javier Aquilué Abadías, Joaquim Tremoleda i Trilla, Enric Sanmartí i Grego, Pere Castanyer i Masoliver y Marta Santos, "El anfiteatro de Emporiae", en Bimilenario del anfiteatro Romano de Mérida. Coloquio Internacional el anfiteatro en la Hispania Romana. Mérida, 26-28 de noviembre de 1992, coord. José María Álvarez Martínez y Juan Javier Enríquez Navascués (Mérida: Junta de Extremadura, 1994), 122.

${ }^{74}$ Golvín, L`Amphitheatre Romain..., 109; Almagro y Almagro-Gorbea, "El anfiteatro de Segobriga...”, 144.

75 Golvín, L Amphitheatre Romain..., 109-111.

76 Manuel Bendala y Rosalia Durán, "El anfiteatro de Augusta Emerita: rasgos arquitectónicos y problemática urbanística y cronología”, en Bimilenario del anfiteatro Romano de Mérida. Coloquio Internacional el anfiteatro en la Hispania Romana. Mérida, 26-28 de noviembre de 1992, coord. José María Álvarez Martínez y Juan Javier Enríquez Navascués (Mérida: Junta de Extremadura, 1994), 249.

${ }^{77}$ Georg Breitner, “Architekturmodelle in der Ausstellung des Rheinischen Landesmuseums Trier”, Funde und Ausgrabungen im Bezirk Trier, v. 43 (2011): 40-41.

78 Lorenzo Cara Barrionuevo y Juana María Rodríguez, "El anfiteatro romano de Villavieja (Berja, Almería)", en XVIII CNA. Las Palmas de Gran Canarias, Santa Cruz de Tenerife, 1985 (Tenerife, 1987), 48-49. 
Almagro, Antonio y Martín Almagro-Gorbea. "El anfiteatro de Segobriga". En Bimilenario del anfiteatro Romano de Mérida. Coloquio Internacional el anfiteatro en la Hispania Romana. Mérida, 26-28 de noviembre de 1992, coordinado por José María Álvarez Martínez y Juan Javier Enríquez Navascués. Mérida: Junta de Extremadura, 1994.

Amela Valverde, Luis. "Pompeius Niger de Italica". Cuadernos de filología clásica: Estudios latinos v. 31, n.1 (2011): 27-35.

Aquilué Abadías, Javier, Joaquim Tremoleda i Trilla, Enric Sanmartí i Grego, Pere Castanyer i Masoliver y Marta Santos, "El anfiteatro de Emporiae". En Bimilenario del anfiteatro Romano de Mérida. Coloquio Internacional el anfiteatro en la Hispania Romana. Mérida, 26-28 de noviembre de 1992, coordinado por José María Álvarez Martínez y Juan Javier Enríquez Navascués. Mérida: Junta de Extremadura, 1994.

Bellido Márquez, Tania. "Panorama historiográfico del anfiteatro de Itálica". Rómula, n. 8 (2009): 33-64.

Beltrán Fortes, José y José Manuel Rodríguez. Itálica: espacios de culto en el anfiteatro. Sevilla: Universidad de Sevilla, 2004.

Beltrán Lloris, Francisco. Lo mejor del Arte Romano I. Madrid: Historia 16, 1997. Bendala, Manuel y Rosalia Durán. "El anfiteatro de Augusta Emerita: rasgos arquitectónicos y problemática urbanística y cronología”. En Bimilenario del anfiteatro Romano de Mérida. Coloquio Internacional el anfiteatro en la Hispania Romana. Mérida, 26-28 de noviembre de 1992, coordinado por José María Álvarez Martínez y Juan Javier Enríquez Navascués. Mérida: Junta de Extremadura, 1994.

Benedetta, Adembri. Villa Adriana. Guida.Roma: Electra, 2000.

Blanco Freijeiro, Antonio. "La Itálica de Trajano y Adriano (Santiponce, Sevilla)".

En: Actas de las primeras jornadas sobre excavaciones arqueológicas en Italica, Exma. Diputación Provincial de Sevilla, 1980. Madrid: Ministerio de Cultura, 1982.

Blázquez, José María. "El urbanismo en Occidente". En Homenaje a Samuel de los Santos. Albacete: Instituto de Estudios Albacetenses, 1988. "Introducción a los escenarios en la antigua Grecia". En Escenarios de España. Fomento de construcciones y contratos, editado por José María Blázquez. Madrid: Biblioteca Virtual Miguel de Cervantes, 2006. "Posibles precedentes prerromanos de los combates de gladiadores romanos". En Bimilenario del anfiteatro Romano de Mérida. Coloquio Internacional el anfiteatro en la Hispania Romana. Mérida, 26-28 de noviembre de 1992, coordinado por José María Álvarez Martínez y Juan Javier Enríquez Navascués. Mérida: Junta de Extremadura, 1994. Religiones en la España antigua. Madrid: Cátedra, 1991.

Boatwright, Mary T. "Itálica y la magnificencia urbana de Adriano". En Itálica MMCC. Actas de las jornadas del 2200 Aniversario de la Fundación de Itálica. Sevilla, 8-11 noviembre 1994, editado por Antonio Caballos Rufino Pilar León. Sevilla: Consejería de cultura, empresa pública de Gestión de programas, 1997. 
Breitner, Georg. "Architekturmodelle in der Ausstellung des Rheinischen Landesmuseums Trier". Funde und Ausgrabungen im Bezirk Trier, v. 43 (2011): 37-43.

Cabrero Piquero, Javier y Félix Cordente Vaquero. "Los oficios de la diversión en Roma”. Espacio, tiempo y forma. Serie II: Historia Antigua, n. 24 (2011): 349366.

Canto, Alicia. "La Vetus Urbs de Italica, quince años después: La planta hipodámica de D. Demetrio de los Ríos, y otras novedades”. CuPAUAM, n. 25 (1999): 145191.

. "Némesis y la localización del circo de Italica". BSAA, n. 52 (1986): 47-81.

Cara Barrionuevo, Lorenzo y Juana María Rodríguez. "El anfiteatro romano de Villavieja (Berja, Almería)". En XVIII CNA. Las Palmas de Gran Canarias, Santa Cruz de Tenerife, 1985. Tenerife, 1987.

Caro, Rodrigo. Antigüedades y principado de la ilustrísima ciudad de Sevilla y Chorographía de su convento jurídico, o antigua cancillería, dirigida al excelentísimo señor Don Gaspar de Guzmán, Conde Duque de Sanlúcar la Mayor. Sevilla: Enrique Bergali, 1634.

Carrasco Gómez, Inmaculada y Alejandro Jiménez Hernández. "A cerca de los edificios de espectáculos en Colonia Augusta Firma Astigi (Écija, Sevilla)". Romula, n. 7 (2008): 7-52.

Carriazo, Juan. "Estado actual de las excavaciones de Itálica: La manzana del gimnasio". Anuario del Cuerpo Facultativo de Archiveros, Bibliotecarios y Arqueólogos, n. 3 (1935).

Ceballos Hornero, Alberto y David Ceballos Hornero. "Los espectáculos del anfiteatro en Hispania”. Iberia v. 6 (2003): 57-70.

Ceballos Hornero, Alberto. "El coste de los espectáculos gladiatorios en las ciudades del occidente romano". Archivo español de Arqueología v. 80 (2007): 107-118. . "Geografía y cronología de los ludi en la Hispania romana". Caesaraugusta, n. 78 (2007): 437-454.

Chisvert Jiménez, Nieves. Topónimos de Italica: urbanismo y arquitectura. Sevilla, 1987.

Corzo Sánchez, Jorge Ramón. "El anfiteatro de Itálica". En Bimilenario del anfiteatro Romano de Mérida. Coloquio Internacional el anfiteatro en la Hispania Romana. Mérida, 26-28 de noviembre de 1992, coordinado por José María Álvarez Martínez y Juan Javier Enríquez Navascués. Mérida: Junta de Extremadura, 1994.

Dadea, Mauro. L'anfiteatro romano di Cagliari. Sassari: Carlo Delfino, 2006.

De los Ríos, Demetrio. Memoria arqueológico-descriptiva del anfiteatro de Itálica. Madrid: Imprenta de José Rodríguez, 1862.

De los Ríos, Rodrigo Amador. "El anfiteatro de Itálica". Revista de Archivos, Bibliotecas y Museos, $3^{a}$ época v. 20, n. 34 (1916). . Excavaciones en el anfiteatro de Itálica. Memoria de los trabajos practicados en 1915. Madrid: Revista de Archivos, Bibliotecas y Museos, 1916. 
Dupré, Xavier. "El anfiteatro de Tarraco". En Bimilenario del anfiteatro Romano de Mérida. Coloquio Internacional el anfiteatro en la Hispania Romana. Mérida, 26-28 de noviembre de 1992, coordinado por José María Álvarez Martínez y Juan Javier Enríquez Navascués. Mérida: Junta de Extremadura, 1994.

Fabié, Antonio María. "El nuevo bronce de Itálica”. Boletín de la Real Academia de la Historia, n. 21 (1892): 385-398.

Flórez, Enrique. España Sagrada. Teatro Geográfico Histórico de la Iglesia de España. Tomo XII: De las Iglesias sufragáneas antiguas de Sevilla: Egabro, Elepla, Eliberi, Italica, Málaga y Tucci. Madrid: Fortanet, 1776.

García Naranjo, Joaquín. El anfiteatro romano de Itálica. Conferencia de divulgación arqueológica. Sevilla: Editorial SE, 1951.

García y Bellido, Antonio. Andalucía Monumental: Itálica. Granada: Editoriales Andaluzas Unidas, 1960.

Garrido Oreno, Javier. "El anfiteatro: una oscura imagen de la antigua Roma". Berceo v. 149 (2005): 153-178.

Golvin, Jean-Claude. L`Amphitheatre Romain. París: Centre Pierre Paris, 1988.

Gómez-Pantoja, Joaquín. "Entre Italia e Hispania: los gladiadores”. En Hiberia-Italia, Italia-Hiberia, editado por Antonio Sartori y Alfredo Valvo. Milán: Cisalpino Istituto Editoriale Universitario, 2006.

Gross, Pierre. "L`amphitheâtre dans la ville. Politique "culturelle" et urbanisme aux deux premiers siècles de l'Empire”. En Bimilenario del anfiteatro Romano de Mérida. Coloquio Internacional el anfiteatro en la Hispania Romana. Mérida, 26-28 de noviembre de 1992, coordinado por José María Álvarez Martínez y Juan Javier Enríquez Navascués. Mérida: Junta de Extremadura, 1994. Hidalgo Prieto, Rafael. "Anfiteatros". En Arte romano de la Bética. Arquitectura y Urbanismo, coordinado por Pilar León. Sevilla: Fundación Focus Abengoa, 2008.

Larrey Hoyuelos, Enrique, Francisco Ramón Girón y Javier Verdugo Santos. "Intervención arqueológica en el anfiteatro de Itálica. Campaña de 1998". Anuario Arqueológico de Andalucía de 1998 v. 3 (1998): 1081-1096.

León Alonso, Pilar. "Las ruinas de Itálica: una estampa arqueológica de prestigio". En La Antigüedad como argumento. Historiografía de Arqueología e Historia Antigua en Andalucía, editado por José Beltrán y Fernando Gascó. Sevilla: Fundación Instituto Gallego, 1993.

León Gómez, Alicia. Imágenes arqueológicas de la España ilustrada. El teatro romano de Sagunto en el siglo XVIII. Sevilla: Universidad de Sevilla, 2006. Luzón, José María. Sevilla la Vieja. Un paseo histórico por las ruinas de Italica. Sevilla: Fundación Focus-Abengoa, 1999.

Marcial, Epigr. 26 y 28.

Medina, Pedro de. Libro de grandezas y cosas memorables de España. Alcalá de Henares: Biblioteca Nacional de Austria, 1566.

Mendoza Álvarez, José David. “Análisis historiográfico del anfiteatro de Itálica”. Tesis doctoral, Universidad de Sevilla, 2017. 
Morales Cara, Manuel. La esclavitud en las colonias romanas de Andalucía. Granada: Universidad de Granada, 2005.

Morales, Ambrosio de. Las angigvedades de las civdades de España. Alcalá de Henares: Real Academia de la Historia, 1575.

Muñoz Garrido, Jaime. El proyecto romano construido en Lusitania. Madrid:

Universidad Politécnica de Madrid, 2002.

Pellicer Catalán, Manuel. "Panorama de la arqueología de Itálica". Boletín de la Real Academia de Bellas Artes de Santa Isabel de Hungría v. 27 (1999): 175-. 202.

Pérez Ballester, José Pedro San Martín y Carmen Berrocal. "El anfiteatro romano de Cartagena (1967-1992)". En Bimilenario del anfiteatro Romano de Mérida.

Coloquio Internacional el anfiteatro en la Hispania Romana. Mérida, 26-28 de noviembre de 1992, coordinado por José María Álvarez Martínez y Juan Javier Enríquez Navascués. Mérida: Junta de Extremadura, 1994.

Pina Polo, Francisco. "Los espectáculos agonísticos en el occidente del Imperio romano". Salduie, n. 7 (2007): 143-156.

Plácido Suárez, Domingo. "Leyes municipales y símbolos del poder: los fundamentos sociales de la dinastía Flavia". Memorias de Historia Antigua, n. 23-24 (20022003): 9-20.

Rodríguez Hidalgo, José Manuel y Simon Keay. "Recent work at Italica". Proceedings of the British Academy, n. 86 (1995): 395-420.

Rodríguez, José Manuel. "Historia de la investigación". En Ciudades romanas de Hispania 7: Italica-Santiponce. Municipium y Colonia Aelia Augusta Italicensium, editado por Antonio Caballos Rufino. Roma: Erma Di Bretschneider, 2010. . "Hitos de una historia gráfica del descubrimiento de Itálica". Itálica, revista de arqueología clásica de Andalucía, n. 2 (2012): 13-28. . "Itálica. La Pompeya Española". En De Pompeya al Nuevo Mundo. La corona española y la arqueología del siglo XVIII. Real Academia de la Historia. Patrimonio Nacional, editado por Martín Almagro y Jorge Maier. Madrid: Real Academia de la Historia, 2012.

Roldán Gómez Lourdes. Técnicas constructivas romanas en Itálica. Santiponce, Sevilla. Madrid: Universidad Autónoma de Madrid, 1993.

- "El anfiteatro de Itálica. Técnicas y materiales de construcción. En Bimilenario del anfiteatro Romano de Mérida. Coloquio Internacional el anfiteatro en la Hispania Romana. Mérida, 26-28 de noviembre de 1992, coordinado por José María Álvarez Martínez y Juan Javier Enríquez Navascués. Mérida: Junta de Extremadura, 1994.

Salas Álvarez, Jesús. "El viaje arqueológico a Andalucía y Portugal de Francisco Pérez Bayer”. SPAL, n. 16 (2007): 9-24. . "La recuperación del patrimonio arqueológico de Andalucía durante la Ilustración (1736-1808)”. Tesis doctoral, Universidad de Sevilla, 2004.

Santos Yanguas, Narciso. "La nueva gladiatura cristiana en el marco de la gladiatura romana”. Hispania Antiqua, n. 32 (2008): 188. 
Solana, José María y Luis Sagredo San Eustaquio. "La política edilicia viaria en Hispania durante el reinado de Adriano". HAnt, n. 30 (2006): 35.

Wilson Jones, Mark. “Designin Amphitheatres". Römische Mitteilungen v. 100 (1993): 391-392. 